\title{
An Evidence based Assessment of Pharmacist's Intervention on Pregnancy Care Knowledge and Practice among the Study Subjects of Dakshina Kannada
}

\author{
Rafna Rafeek PM ${ }^{1}$, Roshna. P $^{1}$, Ateendra Jha ${ }^{2}$, A R Shabaraya ${ }^{3}$ \\ ${ }^{1}$ Student, PharmD, Department of Pharmacy Practice, ${ }^{2}$ Associate Professor, Department of Pharmacy Practice \\ ${ }^{3}$ Professor \& Head, Department of Pharmacy Practice, \\ Srinivas College of Pharmacy, Mangalore, Karnataka-574143 \\ Corresponding Authors: Rafna Rafeek PM, Roshna .P
}

\begin{abstract}
Pregnancy care consists of prenatal (before birth) and postpartum (after birth) healthcare for expectant mothers. Antenatal / prenatal care can be defined as the care provided by trained health-care professionals to pregnant women and adolescent girls in order to make sure the best health conditions for both mother and baby throughout the pregnancy. The components of ANC include: risk identification, prevention and management of pregnancy-related or concurrent diseases, and health education and health promotion. ${ }^{1}$ According to Indian government guidelines, every pregnant should make use of 3 or more antenatal care visits along with 90 or more IFA tablets and 2 or more TT injections. According to joint $\mathrm{WHO}$ and MOD meeting report, birth defects account for $7 \%$ of all neonatal mortality and 3.3 million under five deaths. The prevalence of birth defects in India is 6-7\% which translates to around 1.7 million birth defects annually.

Objectives: The main objective of the study was to find out the knowledge level of the subjects on pregnancy care, to educate the community subjects on pregnancy care and to Evaluate Pregnancy Information leaflet on pregnancy care
\end{abstract}

Methodology: A questionnaire-based interview was executed on 100 study subjects in Mangalore region. Study duration was 6 months. Ethical approval was obtained from Ethics Committee of Srinivas Institute of Medical Science and Research Center. The study population included in the study were adults above 18 years of age, who can understand English/Malayalam and belonging to the family with one or more pregnancy either in past, present or to be in future. Data was analyzed with the help of excel 17 and SPSS 20. Result and Discussion: In our study, survey was carried out on 100 subjects of Mangalore region All the study subjects were female. Out of 100 subjects 58 participants were in between 31 years to 50 Years of age while 19 participants were in 18-30 Years age group. The subjects in the present study do not have adequate knowledge regarding antenatal care, folic acid supplementation, TT injection and dietary change, irrespective to their educational level. The study found that $75 \%$ of the subjects were not aware of the antenatal care and about $100 \%$ were unknown regarding the necessity of antenatal check- up. ANC visit should be an essential part of the antenatal care but our study found that about $13 \%$ of the study subjects were not going for check- up. On pharmacist intervention and proper counselling, in our follow up interview we found that unawareness has reduced to $17 \%$, while $84 \%$ realized the need for check-up.

Conclusion: In our study we found that the respondents do not have adequate knowledge regarding antenatal care, folic acid supplementation, TT injection and dietary change. The age, literacy of the mother significantly influences antenatal care and ANC service utilization. To improve effective utilization of ANC services we need to raise 
awareness through counselling, improve the quality of ANC service, along with effective monitoring and evaluation. Pharmacist plays a major role in increasing awareness among mothers in pregnancy and further emphasizing the importance of ANC.

Keywords: Antenatal care, Knowledge, Awareness

\section{INTRODUCTION}

The American College of Obstetricians and Gynecologists define pregnancy as "The state of a female after conception and until termination of the gestation". Pregnancy also known as gestation is the time during which one or more offspring develops inside women. The National Institute of Health/ Food and Drug Administration defines Pregnancy as Encompassing the period of time from confirmation of implantation until expulsion or extraction of the fetus.

Antenatal Care (ANC) can be defined as the care provided by skilled health-care professionals to pregnant women and adolescent girls in order to ensure the best health conditions for both mother and baby during pregnancy. The components of ANC include: risk identification; prevention and management of pregnancy-related or concurrent diseases; and health education and health promotion. 1

A typical pregnancy lasts 40 weeks from the first day of your last menstrual period (LMP) to the birth of the baby. Pregnancy has three trimesters, each of which is marked by specific fetal developments. $^{2}$

First Trimester (0 to 13 Weeks)

Second Trimester (14 to 26 Weeks)

Third Trimester (27 to 40 Weeks)

According to Indian government guidelines, every pregnant should avail for 3 or more antenatal care visits along with 90 or more Iron and Folic acid (IFA) tablets and 2 or more TT injections. Antenatal care visits are crucial in reducing neonatal mortality, especially in developing countries. First ANC visit of pregnant mothers should be in the first trimester for better health of new-born. WHO recommended for all pregnant women to have four consecutive ANC visits for low risk pregnant women. ${ }^{3}$

Daily oral iron and folic acid supplementation with $30 \mathrm{mg}$ to $60 \mathrm{mg}$ of elemental iron and $400 \mu \mathrm{g}(0.4 \mathrm{mg})$ folic acid is recommended for pregnant women to prevent maternal anemia, puerperal sepsis, low birth weight, and preterm birth. And it becomes more beneficial if mother starts taking folic acid before getting pregnant. ${ }^{4}$

Immunization during pregnancy is a simple and effective way to protect the mother and child from certain infections via transfer of antibodies from the mother to the fetus. Vaccination of pregnant women can protect mother against vaccine-preventable infections, and in so doing potentially protect the fetus. The World Health Organization (WHO) reported that neonatal tetanus kills over 200,000 new-born each year; almost all these deaths occur in developing countries while it is very rare in developed nations. Tetanus toxoids appear safe during pregnancy and are administered in many countries of the world to prevent neonatal tetanus. The first dose of tetanus toxoid should be administered as soon as pregnancy is detected, second dose of tetanus toxoid is administered after 4 weeks and if a mother received 2 TT doses in the last pregnancy and mother gets again pregnant with in 3 years than only one dose of TT is recommended and that dose is called booster dose. ${ }^{5}$

According to 2017 study there were 193 births per 1000 population out of that still birth was reported in 73 cases. Getting good care before, during, and after pregnancy is very important for growth and development of baby as well as it will keep mother also healthy. ${ }^{6}$

Nutrition is important in pregnancy. Eating a nutritious diet during pregnancy is linked to good fetal brain development, a healthy birth weight, and it reduces the risk of many birth defects. A balanced diet will also reduce the risks of anemia, as well as 
other unpleasant pregnancy symptoms such as fatigue and morning sickness. For the welfare of mother and baby it is advisable to avoid vigorous activity that could involve a risk of falling or overheating. Unpasteurized milk and soft cheeses, fish high in mercury, or raw or undercooked foods including fish and eggs should be avoided. Mothers should stay away from heavy lifting and bending. It is advisable to avoid X-rays exposure during pregnancy. ${ }^{7}$

Alcohol in the mother's blood passes to the baby through the umbilical cord. Drinking alcohol during pregnancy can cause miscarriage, stillbirth, and a range of lifelong physical, behavioral, and intellectual disabilities. These disabilities are known as fetal alcohol spectrum disorders (FASDs). ${ }^{8}$

Tobacco smoking in pregnancy is dangerous for both mother and baby. Smoking during pregnancy is associated with pregnancy complications, such as preeclampsia, placenta previa, and placental abruption, and with poor fetal outcomes such as low birth weight, premature birth, stillbirth, sudden infant death syndrome, and high overall perinatal mortality. Nicotine and all the harmful (and cancer- causing) products inhaled from the tobacco enter the bloodstream of the mother and are passed directly into the baby's circulation through the placenta. ${ }^{9}$

Globally, complications during pregnancy, childbirth, and the postnatal period have been the leading causes of death and disability among reproductive age women. Maternal deaths can be reduced if women can access quality medical care during pregnancy, childbirth, and postpartum. The quality of prenatal care has an important role in the prevention, monitoring, early detection, and treatment of maternal health problems, enhancing maternal satisfaction, and healthcare utilization.

Good quality antenatal care (ANC) reduces maternal and neonatal mortality and improves health outcomes, particularly in low-income countries. Quality of ANC is measured by three dimensions: number of visits, timing of initiation of care and inclusion of all recommended components of care. ${ }^{10}$

\section{MATERIALS \& METHODS}

Study Site: Dakshina Kannada

Study Design: Interventional Study

Sample Size: The study was limited for a sample of 100 patients based on the time schedule allotted for the project including other circumstances.

Study Duration: Study was conducted for duration of 6 months. (September 2019 to March 2020)

\section{Ethical clearance:}

The protocol for the study was approved by the Institutional Ethics Committee (IEC) of Srinivas Institute of Medical Science, Mukka, Mangalore (Ref no: 2019/10/28/4).

\section{Study Criteria: \\ Inclusion criteria:}

Subjects more than 18 years old, can understand English/Malayalam and Subject's belonging to the family with one or more pregnancy either in past, present or to be in future

\section{Exclusion criteria:}

Subjects less than 18 years old, cannot English/Malayalam and or Subjects from the family of only man/men

\section{Preparation of inform consent form (ICF)}

Inform consent form was prepared in Kannada and English and the same was used. The consent form was orally explained to the participants before filling it

\section{Development of questionnaire:}

A set of questions was designed as a tool for assessing the knowledge and practices regarding pregnancy care

\section{OPERATION MODALITY}

The relevant data of the subjects was collected using a data collection form. The 
Rafna Rafeek PM et.al. An evidence based assessment of pharmacist's intervention on pregnancy care knowledge and practice among the study subjects of Dakshina Kannada.

collected data was analyzed using excel 17 and SPSS 20.

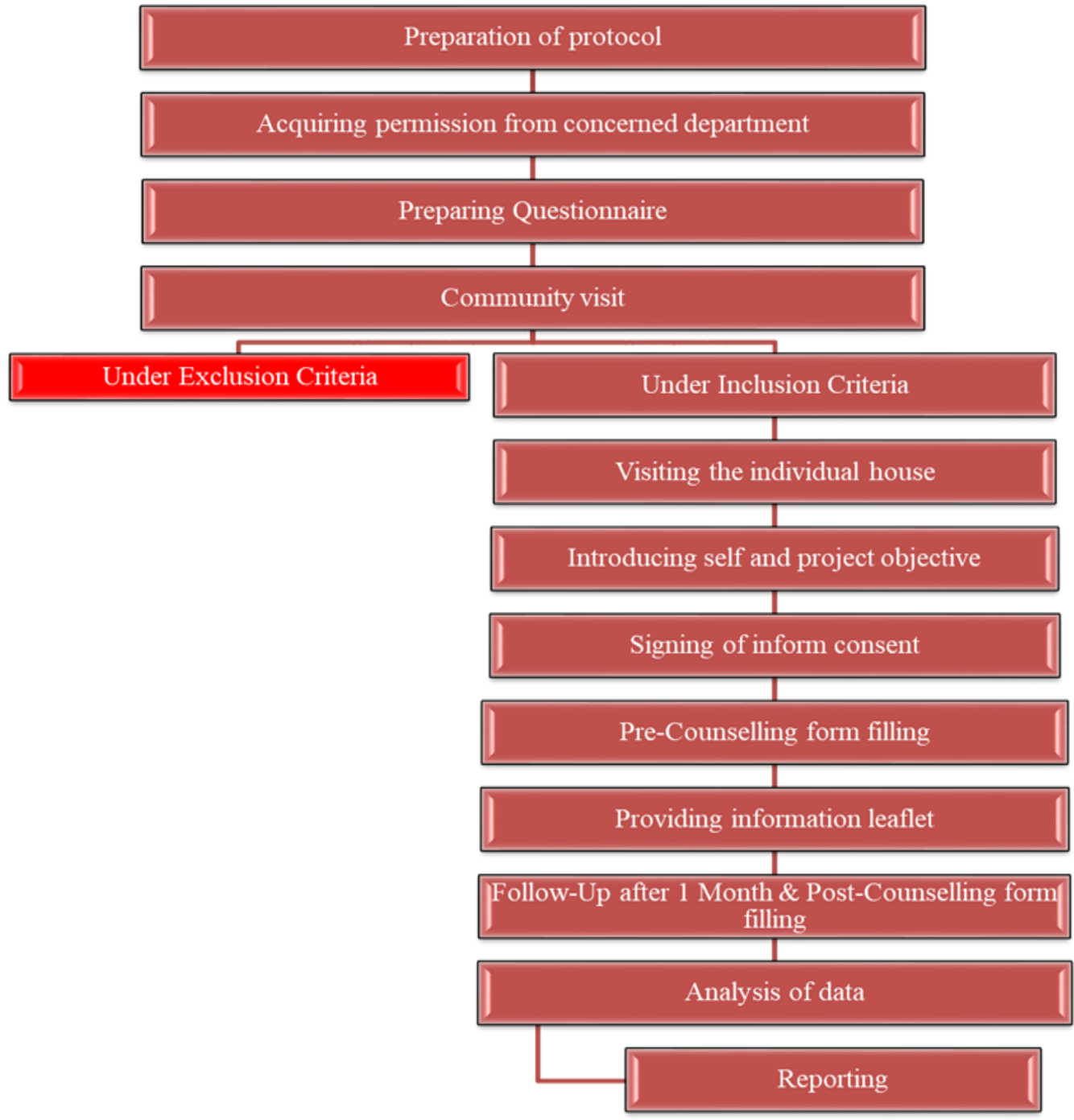

RESULT

Demographic Characteristic of Participants:

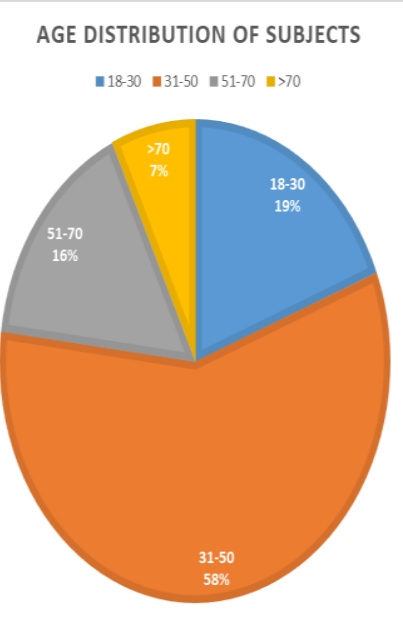

Figure1: Age distribution of subjects
Our study enrolled about 100 subjects from different areas of Dakshina Kannada. All the study subjects were female. Out of 100 subjects majority (58) were in between 31 years to 50 Years of age, while 19 participants were in 18-30 Years age group. (Figure: 1)

On the analysis of marriage age, we found 50 got married in between 21-25 years, while 18 subjects were in age group of 25-30. We also found that 5 got married after 30 Years and 13 were married before18 years. Subjects married between 18 years to 21 years were 14 in count. (Figure: 2) 
Rafna Rafeek PM et.al. An evidence based assessment of pharmacist's intervention on pregnancy care knowledge and practice among the study subjects of Dakshina Kannada.

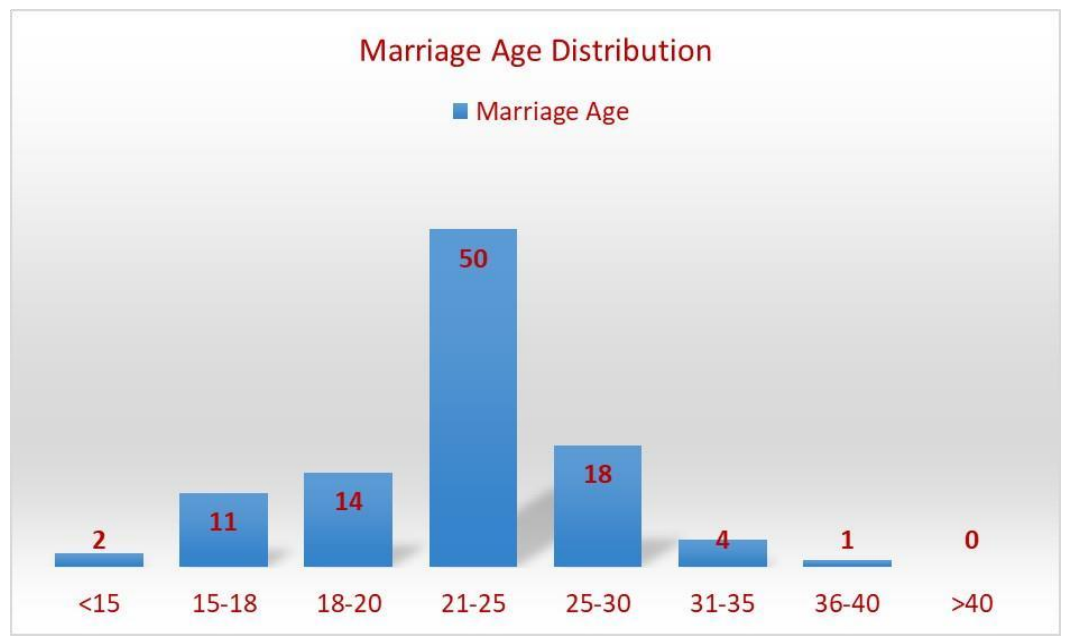

Figure 2: Distribution of subjects according to their marriage age.

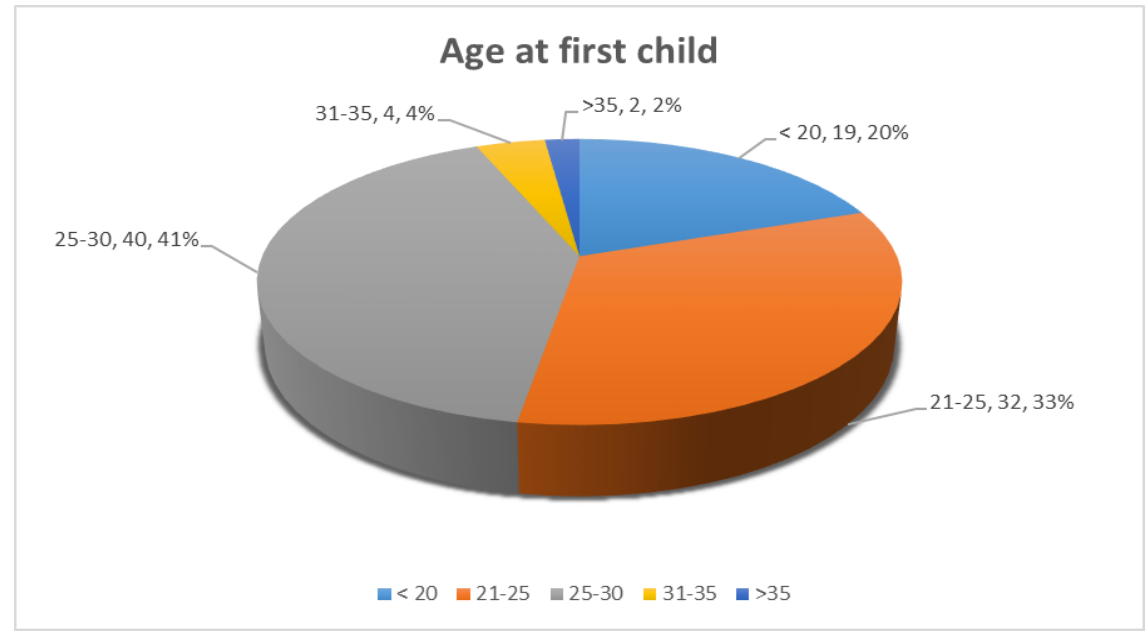

Figure 3: Distribution of age at first child.

Out of 100 participants 38 participants had their first child during the age group of 25-30, 32 participants had their child during the age group of 21-25, and 14 participants had their child during 18-20 years of age, 4 participants had their first child when they were less than 18 years of old. The 6 participants had their first child when they were greater than 30 years of age. (Figure :3)

\section{ASSESSMENT OF KNOWLEDGE:}

\section{Knowledge Regarding Antenatal Care:}

From the study conducted, understanding of antenatal care, out of 100 participants, $75 \%$ answered wrong initially, which substantially reduced to $17 \%$ participants after the counselling. The present study confirmed that out of 100 participants $100 \%$ responded wrong regarding the necessity of antenatal checkup but after counselling it was narrowed to $16 \%$. 39\% of participants replied incorrect regarding the first antenatal check-ups but after giving the correct information, the percentage of the wrong answer reduced to $15 \%$. (Table 1)

While evaluating the knowledge regarding the number of antenatal check-up required, $66 \%$ of the participants answered incorrect, which after the counselling slashed to $12 \%$. During the assessment of necessity of antenatal care, we observed that $73 \%$ of participants answered wrong, which was later reduced to $8 \%$. (Table: 1 )

It is inferred that $84 \%$ answered wrong initially for the question if antenatal booking should be done before the third month of pregnancy but after counselling the percentage narrowed down to $8 \%$. And 
Rafna Rafeek PM et.al. An evidence based assessment of pharmacist's intervention on pregnancy care knowledge and practice among the study subjects of Dakshina Kannada.

later for analyzing the knowledge on antenatal follow up good for monitoring mothers and fetal health $79 \%$ answered incorrect, but after counselling percentage of the wrong answer reduced to $7 \%$. (Table: 1)

\begin{tabular}{|c|c|c|c|c|c|c|c|c|}
\hline \multirow{3}{*}{\multicolumn{2}{|c|}{ ASSESSMENT QUESTIONS }} & \multicolumn{5}{|c|}{ PRE / POST } & \multirow{3}{*}{$\begin{array}{l}\text { Chi- } \\
\text { square }\end{array}$} & \multirow[b]{3}{*}{$p$ value } \\
\hline & & \multicolumn{2}{|c|}{ Pre $(\mathrm{N}=100)$} & \multicolumn{2}{|c|}{ Post $(\mathrm{N}=100)$} & \multirow{2}{*}{$\begin{array}{l}\text { Total } \\
\text { Count } \\
\end{array}$} & & \\
\hline & & Count & $\%$ & Count & $\%$ & & & \\
\hline \multirow{2}{*}{ What Do You Understand By Antenatal Care? } & Wrong & 75 & $75 \%$ & 17 & $17 \%$ & 92 & \multirow[b]{2}{*}{67.71} & \multirow[b]{2}{*}{$<0.00001$} \\
\hline & Correct & 25 & $25 \%$ & 83 & $83 \%$ & 108 & & \\
\hline \multirow[t]{2}{*}{ Necessity Of Antenatal Check Up } & Wrong & 100 & $100 \%$ & 16 & $16 \%$ & 116 & \multirow[b]{2}{*}{144.82} & \multirow[b]{2}{*}{$<0.00001$} \\
\hline & Correct & 0 & $0.0 \%$ & 84 & $84 \%$ & 84 & & \\
\hline \multirow{2}{*}{$\begin{array}{l}\text { Should First Antenatal Check-Up Should Be Done } \\
\text { During The First } 3 \text { Months }\end{array}$} & Wrong & 39 & $39 \%$ & 15 & $15 \%$ & 54 & \multirow[b]{2}{*}{14.61} & \multirow[b]{2}{*}{$<0.00001$} \\
\hline & Correct & 61 & $61 \%$ & 85 & $85 \%$ & 146 & & \\
\hline \multirow[t]{2}{*}{ Should Come For At Least 5 Antenatal Check-Ups? } & Wrong & 66 & $66 \%$ & 12 & $12 \%$ & 78 & \multirow[b]{2}{*}{61.28} & \multirow[b]{2}{*}{$<0.00001$} \\
\hline & Correct & 34 & $34 \%$ & 88 & $88 \%$ & 122 & & \\
\hline \multirow{2}{*}{ Is Antenatal Check-Up Nec- essary? } & Wrong & 73 & $73 \%$ & 8 & $8 \%$ & 81 & \multirow[b]{2}{*}{87.66} & \multirow[b]{2}{*}{$<0.00001$} \\
\hline & Correct & 27 & $27 \%$ & 92 & $92 \%$ & 119 & & \\
\hline \multirow{2}{*}{$\begin{array}{l}\text { Antenatal Follow Up Is Good } \\
\text { To Monitor Mothers And Foe- tus Health }\end{array}$} & Wrong & 79 & $79 \%$ & 7 & $7 \%$ & 86 & \multirow[b]{2}{*}{105.75} & \multirow[b]{2}{*}{$<0.00001$} \\
\hline & Correct & 21 & $21 \%$ & 93 & $93 \%$ & 114 & & \\
\hline \multirow{2}{*}{$\begin{array}{l}\text { Antenatal Booking Should Be } \\
\text { Done Before The Third Month Of Pregnancy? }\end{array}$} & Wrong & 84 & $84 \%$ & 8 & $8 \%$ & 92 & \multirow[b]{2}{*}{116.26} & \multirow[b]{2}{*}{$<0.00001$} \\
\hline & Correct & 16 & $16 \%$ & 92 & $92 \%$ & 108 & & \\
\hline
\end{tabular}

KNOWLEDGE REGARDING

\section{SCREENING TEST IN PREGNANCY:}

While analyzing the knowledge of the study subjects regarding the screening tests in pregnancy many of them were unaware. $49 \%$ of participants answered wrong regarding Hepatitis B screening and after counselling it was reduced to $11 \% .48$ $\%$ of the participants were oblivious of HIV infection, after giving the right information it was lowered to $7 \% .44 \%$ of participants answered wrong regarding the haemoglobin screening but after counselling it was slashed to 8\%. (Table:2)

$23 \%$ of participants were not aware of $\mathrm{BP}$ examination, $81 \%$ of participants answered wrong regarding the regular BP check-up, $32 \%$ of the participants answered incorrect in the question whether foetal growth can be affected by high BP. But after counselling it was reduced to $6 \%$ in $\mathrm{BP}$ examination, $7 \%$ in regular BP check-up and $28 \%$ whether foetal growth can be affected by high BP respectively. (Table:2)

$27 \%$ of the participants answered incorrect regarding the blood sugar examination and after counselling it was reduced to $6 \%$.While answering the question concerning examining of blood for the infection $86 \%$ answered wrong at first after counselling it was reduced to $7 \%$. (Table:2)

Table2: Knowledge Regarding Screening Test In Pregnancy:

\begin{tabular}{|c|c|c|c|c|c|c|c|c|}
\hline \multirow[t]{3}{*}{ ASSESSMENT QUESTIONS } & & \multicolumn{5}{|c|}{ PRE / POST } & \multirow{3}{*}{$\begin{array}{l}\text { Chi } \\
\text { square }\end{array}$} & \multirow[t]{3}{*}{ p value } \\
\hline & & \multicolumn{2}{|c|}{ Pre $(\mathrm{N}=100)$} & \multicolumn{2}{|c|}{ Post $(\mathrm{N}=100)$} & \multirow{2}{*}{$\begin{array}{l}\text { Total } \\
\text { Count } \\
\end{array}$} & & \\
\hline & & Count & $\%$ & Count & $\%$ & & & \\
\hline \multirow{2}{*}{ Blood Screening For Hepa- titis B? } & Wrong & 49 & $49 \%$ & 11 & $11 \%$ & 60 & \multirow[b]{2}{*}{34.381} & \multirow[t]{2}{*}{$<0.00001$} \\
\hline & Correct & 51 & $51 \%$ & 89 & $89 \%$ & 140 & & \\
\hline \multirow{2}{*}{ Blood Screening For HIV Infection? } & Wrong & 48 & $48 \%$ & 7 & $7 \%$ & 55 & \multirow[b]{2}{*}{42.157} & \multirow[t]{2}{*}{$<0.00001$} \\
\hline & Correct & 52 & $52 \%$ & 93 & $93 \%$ & 145 & & \\
\hline \multirow[t]{2}{*}{ Blood Screening For Hae- 22yoglobin Level? } & Wrong & 44 & $44 \%$ & 8 & $8 \%$ & 52 & \multirow[b]{2}{*}{33.680} & \multirow[t]{2}{*}{$<0.00001$} \\
\hline & Correct & 56 & $56 \%$ & 92 & $92 \%$ & 148 & & \\
\hline \multirow[b]{2}{*}{ BP Examination } & Wrong & 23 & $23 \%$ & 6 & $6 \%$ & 29 & \multirow[b]{2}{*}{11.656} & \multirow{2}{*}{$.001^{*}$} \\
\hline & Correct & 77 & $77 \%$ & 94 & $94 \%$ & 171 & & \\
\hline \multirow[b]{2}{*}{ Blood Sugar Examination } & Wrong & 27 & $27 \%$ & 6 & $6 \%$ & 33 & \multirow[b]{2}{*}{16.004} & \multirow[t]{2}{*}{$<0.00001$} \\
\hline & Correct & 73 & $73 \%$ & 94 & $94 \%$ & 167 & & \\
\hline \multirow[t]{2}{*}{ Can High BP Affect Foetal Growth } & Wrong & 32 & $32 \%$ & 28 & $28 \%$ & 60 & \multirow[b]{2}{*}{.381} & \multirow[t]{2}{*}{$>0.5$} \\
\hline & Correct & 68 & $68 \%$ & 72 & $72 \%$ & 140 & & \\
\hline \multirow{3}{*}{$\begin{array}{l}\text { Screening Of Blood For Infection Should Be Carried Out } \\
\text { During Check-up? }\end{array}$} & Wrong & 86 & $86 \%$ & 7 & $7 \%$ & 93 & \multirow{3}{*}{125.43} & \multirow[t]{3}{*}{$<0.00001$} \\
\hline & Correct & 14 & $14 \%$ & 93 & $93 \%$ & 107 & & \\
\hline & Correct & 19 & $19 \%$ & 93 & $93 \%$ & 112 & & \\
\hline
\end{tabular}

\section{KNOWLEDGE REGARDING INJECTION TT:}

From the study conducted in a total of 100 participants only $12 \%$ was aware 
Rafna Rafeek PM et.al. An evidence based assessment of pharmacist's intervention on pregnancy care knowledge and practice among the study subjects of Dakshina Kannada.

about the need of injection TT. But after counselling it was increased to $85 \%$ that is before counselling $88 \%$ was wrong after that it got reduced to $15 \%$.(Table :3)

In assessing the knowledge part of the study participants regarding the total dose of the injection TT during the pregnancy before counselling the rate of wrong answers was $85 \%$ after counselling it reduced to $20 \%$ and also initially only 15 $\%$ participants was correct and after counselling it increased to $80 \%$. (Table :3)

Table 3: Knowledge regarding injection TT

\begin{tabular}{|c|c|c|c|c|c|c|c|c|}
\hline \multirow{2}{*}{\multicolumn{2}{|c|}{ ASSESSMENT QUESTIONS }} & \multicolumn{5}{|c|}{ PRE / POST } & \multirow{3}{*}{ Chi- square } & \multirow{3}{*}{ p value } \\
\hline & & \multicolumn{2}{|c|}{ Pre $(\mathrm{N}=100)$} & \multicolumn{2}{|c|}{ Post $(\mathrm{N}=100)$} & \multirow{2}{*}{$\begin{array}{l}\text { Total } \\
\text { Count }\end{array}$} & & \\
\hline & & Count & $\mathbf{N} \%$ & Count & $\mathbf{N} \%$ & & & \\
\hline \multirow[t]{2}{*}{ Necessity of Injection TT? } & Wrong & 88 & $88 \%$ & 15 & $15 \%$ & 103 & \multirow[b]{2}{*}{106.67} & \multirow[b]{2}{*}{$<0.00001$} \\
\hline & Correct & 12 & $12 \%$ & 85 & $85 \%$ & 97 & & \\
\hline \multirow[t]{2}{*}{ How Many Dose Of Injection TT? } & Wrong & 85 & $85 \%$ & 20 & $20 \%$ & 105 & \multirow[b]{2}{*}{84.71} & \multirow[b]{2}{*}{$<0.0001$} \\
\hline & Correct & 15 & $15 \%$ & 80 & $80 \%$ & 95 & & \\
\hline
\end{tabular}

\section{KNOWLEDGE REGARDING IRON AND FOLIC ACID IN PREGNANCY}

In our study for accessing the need of folic acid tablet to women, we found that out of 100 participants many of them are unaware that is $91 \%$ answered wrong initially. But after counselling percentage of wrong answer reduced to $29 \%$. (Table 4)
Study carried out in100 participants regarding whether the supplementation of iron and folic acid is good for mother and foetus, we found that majority that is $87 \%$ answered wrong initially .But after counselling percentage of wrong answer reduced to $36 \%$.(Table 4 )

Table 4: Knowledge Regarding Iron And Folic Acid In Pregnancy

\begin{tabular}{|c|c|c|c|c|c|c|c|}
\hline \multirow[t]{3}{*}{ ASSESSMENT QUESTIONS } & & \multicolumn{4}{|c|}{ Pre / Post } & \multirow{3}{*}{$\begin{array}{l}\text { Chi- } \\
\text { square }\end{array}$} & \multirow{3}{*}{ p value } \\
\hline & & \multicolumn{2}{|c|}{ Pre $(\mathrm{N}=100)$} & \multicolumn{2}{|c|}{ Post $(\mathrm{N}=100)$} & & \\
\hline & & Count & $\%$ & Count & $\%$ & & \\
\hline \multirow[t]{2}{*}{ Why Iron And Folic Acid Tablets Given To Pregnant Women? } & Wrong & 91 & $91 \%$ & 29 & $29 \%$ & \multirow[t]{2}{*}{80.083} & \multirow[t]{2}{*}{$<0.00001$} \\
\hline & Correct & 9 & $9 \%$ & 71 & $71 \%$ & & \\
\hline \multirow{2}{*}{$\begin{array}{l}\text { Supplementation Of Iron And Folic Acid Good For Mother And } \\
\text { Foetus? }\end{array}$} & Wrong & 87 & $87 \%$ & 36 & $36 \%$ & \multirow[t]{2}{*}{54.926} & \multirow[t]{2}{*}{$<0.00001$} \\
\hline & Correct & 13 & $13 \%$ & 64 & $64 \%$ & & \\
\hline
\end{tabular}

KNOWLEDGE REGARDING SOCIAL HABITS IN PREGNANCY

While assessing the knowledge part of the study participants regarding the smoking habit in pregnancy out of 100 participants, $35 \%$ answered wrong initially that is they were not agreeing to the fact that smoking harmful to the foetus. But after counselling percentage of wrong answer reduced to $6 \%$. (Table 5)In accessing knowledge regarding whether the alcohol consumption affect foetal growth, out of 100 participants we found that $37 \%$ answered wrong initially that is they were agreeing to the statement. But after counselling, percentage of wrong answer reduced to $4 \%$. (Table 5)

\begin{tabular}{|c|c|c|c|c|c|c|c|c|}
\hline \multirow[b]{3}{*}{ ASSESSMENT QUESTIONS } & & \multicolumn{5}{|c|}{ Pre / Post } & \multirow{3}{*}{$\begin{array}{l}\text { Chi- } \\
\text { square }\end{array}$} & \multirow{3}{*}{ p value } \\
\hline & & \multicolumn{2}{|c|}{ Pre $(\mathrm{N}=100)$} & \multicolumn{2}{|c|}{ Post $(\mathrm{N}=100)$} & \multirow{2}{*}{$\begin{array}{l}\text { Total } \\
\text { Count }\end{array}$} & & \\
\hline & & Count & $\begin{array}{ll}\text { Row } & \mathbf{N} \\
\% & \\
\end{array}$ & Count & $\begin{array}{ll}\text { Row } & \mathbf{N} \\
\% & \\
\end{array}$ & & & \\
\hline \multirow[t]{2}{*}{ Smoking Harmful To The Foetus? } & Wrong & 35 & $35 \%$ & 6 & $.6 \%$ & 41 & \multirow[b]{2}{*}{25.802} & \multirow[b]{2}{*}{$<0.00001$} \\
\hline & Correct & 65 & $65 \%$ & 94 & $94 \%$ & 159 & & \\
\hline \multirow{2}{*}{$\begin{array}{l}\text { Alcohol Consumption } \text { Affect } \\
\text { Growth? }\end{array}$} & Wrong & 37 & $37 \%$ & 4 & $4 \%$ & 41 & \multirow[b]{2}{*}{33.410} & \multirow[b]{2}{*}{$<0.00001$} \\
\hline & Correct & 63 & $63 \%$ & 96 & $96 \%$ & 159 & & \\
\hline
\end{tabular}

KNOWLEDGE REGARDING DRUG AND HEALTHY LIFESTYLE:

From the total of 100 participants, regarding the effect of infection on the foetus during pregnancy, $39 \%$ were not aware about that infections during pregnancy cause harmful to baby. But after counselling, percentage of wrong answer reduced to $5 \%$. 
While assessing the knowledge level of the participants regarding the intake of medications other than the prescribed medication out of 100 participants ,44\% were not aware about that any medicines other than prescribed can cause harm to baby. But after counselling, percentage of wrong answer reduced to $6 \%$. (Table 6)

While assessing the study about the knowledge regarding the place of delivery of the baby among the 100 participants about $22 \%$ initially answered but after counselling it got reduced to $6 \%$.

While assessing the knowledge of the participants regarding the awareness about any case of medical emergency during pregnancy from our study we found that among 100 participants $30 \%$ answered wrong initially that is they are not aware about the steps but after counselling percentage of the wrong answer reduced to $7 \%$.(Table 6)

From our study we came to know that many of them are unaware regarding the need of USG in pregnancy that is among the 100 participants only $15 \%$ answered correct initially after counselling it was increased to $92 \%$ about $85 \%$ was wrong initially after it got reduced to $8 \%$.(Table 6)

While assessing the dietary habits in pregnancy we came to know that among the 100 participants only $17 \%$ was correct that is they used to follow dietary habits according to the doctor's instruction, after counselling it became $93 \%$.(Table 6)

Table: 6 Knowledge regarding drug and healthy lifestyle.

\begin{tabular}{|c|c|c|c|c|c|c|c|}
\hline \multirow{3}{*}{\multicolumn{2}{|c|}{ ASSESSMENT QUESTIONS }} & \multicolumn{4}{|c|}{ PRE / POST } & \multirow{3}{*}{$\begin{array}{l}\text { Chi- } \\
\text { square }\end{array}$} & \multirow{3}{*}{ p value } \\
\hline & & \multicolumn{2}{|c|}{ Pre $(\mathrm{N}=100)$} & \multicolumn{2}{|c|}{ Post $(\mathrm{N}=100)$} & & \\
\hline & & Count & $\%$ & Count & $\%$ & & \\
\hline \multirow{2}{*}{ Infection During Pregnancy Cause Harmful } & Wrong & 39 & $39 \%$ & 5 & $5 \%$ & \multirow[b]{2}{*}{33.683} & \multirow[b]{2}{*}{$<0.00001$} \\
\hline & Correct & 61 & $61 \%$ & 95 & $95 \%$ & & \\
\hline \multirow{2}{*}{$\begin{array}{l}\text { Any Medicines Other Than Prescribed Can Cause Harm To } \\
\text { Baby? }\end{array}$} & Wrong & 44 & $44 \%$ & 6 & $6 \%$ & \multirow[b]{2}{*}{38.507} & \multirow[b]{2}{*}{$<0.00001$} \\
\hline & Correct & 56 & $56 \%$ & 94 & $94 \%$ & & \\
\hline \multirow[b]{2}{*}{ Where To Deliver Baby? } & Wrong & 22 & $22 \%$ & 6 & $6 \%$ & \multirow[b]{2}{*}{10.631} & \multirow[b]{2}{*}{$<0.00001$} \\
\hline & Correct & 78 & $78 \%$ & 94 & $94 \%$ & & \\
\hline \multirow{2}{*}{$\begin{array}{l}\text { Any Problem During } \\
\text { Pregnancy, What Will You Do? }\end{array}$} & Wrong & 30 & $30 \%$ & 7 & $7 \%$ & \multirow[b]{2}{*}{17.543} & \multirow[b]{2}{*}{$<0.00001$} \\
\hline & Correct & 70 & $70 \%$ & 93 & $93 \%$ & & \\
\hline \multirow{2}{*}{$\begin{array}{l}\text { Should Undergo USG As Advised By } \\
\text { Doctor }\end{array}$} & Wrong & 85 & $85 \%$ & 8 & $8 \%$ & \multirow[b]{2}{*}{119.164} & \multirow[b]{2}{*}{$<0.00001$} \\
\hline & Correct & 15 & $15 \%$ & 92 & $92 \%$ & & \\
\hline \multirow{2}{*}{$\begin{array}{l}\text { Should Change Dietary } \\
\text { Habit As Advised By Doctor. }\end{array}$} & Wrong & 83 & $83 \%$ & 7 & $7 \%$ & \multirow[b]{2}{*}{116.687} & \multirow[b]{2}{*}{$<0.00001$} \\
\hline & Correct & 17 & $17 \%$ & 93 & $93 \%$ & & \\
\hline
\end{tabular}

\section{PRACTICES OF STUDY SUBJECTS DURING PREGNANCY PRACTICES REGARDING ANC AND TT}

In our present study, while assessing the practice section out of 100 participants, 46 participants had their antenatal check-up during $1^{\text {st }}-2^{\text {nd }}$ months, 31 participants had antenatal check-up during $2^{\text {nd }}-3^{\text {rd }}$ month, 11 participants had their check-up during $3^{\text {rd }}$ $4^{\text {th }}$ month, 7 participants had their check-up after $4^{\text {th }}$ month. 83 participants were regular in the ANC check-up, 13 participants were irregular in the ANC check-up. (Table 7)

While assessing the main factor for the regular ANC check-up out of 100 participants 51 participants had their regular visit for the care of baby, 26 participants had their regular visit because they want to know about medical care , 7 participants had their regular visit because of the advice of the doctor, 1 participant had their regular visit both for the care of the baby as well as to know about medical care, 1 participant had their regular visit because she was advised by doctor as well as to know about the medical care. (Table 7)

The reason behind the irregular ANC visit were, 3 participants had transport problem, 1 participant had family refusal, 1 participant was not there in the station and 8 participants did not feel like going for ANC check-up. (Table 7)

While evaluating regarding the number of ANC visit during the pregnancy, 8 participant had 1 ANC check-up , 3 participants had 2 ANC check-up, 21 
Rafna Rafeek PM et.al. An evidence based assessment of pharmacist's intervention on pregnancy care knowledge and practice among the study subjects of Dakshina Kannada.

participant had 3 ANC check-up, 34 participant had 4 ANC check-up, 19 participants had 5 ANC check-up, 7 participant had more than 5 ANC check up. (Table 7)
Out of 100 participants, 45 participants had 3 doses of injection TT, 15 participants had 2 doses of injection TT and10 participants had 1 dose of injection TT, 18 participants has not taken any injection TT.(Table 7)

Table: 7 Practices Regarding ANC and TT

\begin{tabular}{|c|c|c|c|}
\hline & & COUNT & $\begin{array}{l}\text { COLUMN } \\
\text { N \% }\end{array}$ \\
\hline \multirow{6}{*}{$\begin{array}{l}\text { At what duration of pregnancy you visited health centre for } \\
\text { check- up? }\end{array}$} & Between1-2month & 46 & $46.0 \%$ \\
\hline & 2-3month & 31 & $31.0 \%$ \\
\hline & $3-4$ months & 11 & $11.0 \%$ \\
\hline & Others & 7 & $7.0 \%$ \\
\hline & Not applicable & 5 & $5.0 \%$ \\
\hline & Total & 100 & $100.0 \%$ \\
\hline \multirow[t]{4}{*}{ Are you regular in ANC check-up? } & Yes & 83 & $83.0 \%$ \\
\hline & No & 13 & $13.0 \%$ \\
\hline & Not applicable & 4 & $4.0 \%$ \\
\hline & Total & 100 & $100.0 \%$ \\
\hline \multirow[t]{7}{*}{ Main factor behind regular visit? } & For care of baby & 51 & $51.0 \%$ \\
\hline & To know about medical care & 26 & $26.0 \%$ \\
\hline & Doctor's advice & 7 & $7.0 \%$ \\
\hline & Not applicable & 14 & $14.0 \%$ \\
\hline & For care of baby, To know about medical care & 1 & $1.0 \%$ \\
\hline & To know about medical care, doctor's advice & 1 & $1.0 \%$ \\
\hline & Total & 100 & $100.0 \%$ \\
\hline \multirow[t]{6}{*}{ Reason for irregular visit? } & Transport problem & 3 & $3.0 \%$ \\
\hline & Family refusal & 1 & $1.0 \%$ \\
\hline & Not in station & 1 & $1.0 \%$ \\
\hline & Did not feel like & 8 & $8.0 \%$ \\
\hline & Not applicable & 87 & $87.0 \%$ \\
\hline & Total & 100 & $100.0 \%$ \\
\hline \multirow[t]{8}{*}{ Number of ANC visit? } & 1 & 8 & $8.0 \%$ \\
\hline & 2 & 3 & $3.0 \%$ \\
\hline & 3 & 21 & $21.0 \%$ \\
\hline & 4 & 34 & $34.0 \%$ \\
\hline & 5 & 19 & $19.0 \%$ \\
\hline & More than 5 & 7 & $7.0 \%$ \\
\hline & Not applicable & 8 & $8.0 \%$ \\
\hline & Total & 100 & $100.0 \%$ \\
\hline \multirow[t]{6}{*}{ Number of TT dose? } & 1 & 10 & $10.0 \%$ \\
\hline & 2 & 15 & $15.0 \%$ \\
\hline & 3 & 45 & $45.0 \%$ \\
\hline & None & 18 & $18.0 \%$ \\
\hline & Not applicable & 12 & $12.0 \%$ \\
\hline & Total & 100 & $100.0 \%$ \\
\hline
\end{tabular}

\section{DISCUSSION}

The care that was given to the mother during pregnancy, during delivery, and after delivery is important for the wellbeing of the mother and the child. ANC is an effective tool to reduce both infant and maternal mortality rates. According to the study done in rural area of North India by Gupta RK et al., the respondents had adequate knowledge about ANC services because the respondent's literacy level was high. ${ }^{3}$ But in our study we found that the subjects in higher qualification were also not aware regarding the antenatal care, folic acid supplementation, TT injection and dietary change. In our study $60 \%$ subjects had qualification above post-graduation while $40 \%$ subjects had qualification below under graduation.

The present study was done population of 100 participants from different places of Dakshina Kannada. Our study found that majority, about 58\% of participants were among 31-50 age groups while 19 participants of 18-30 age groups.

On the analysis of age of marriage we found that majority, $68 \%$ of participants married during the age group of 21-30 while 
$27 \%$ of subjects got married at the age under 20 years. According to the Health - Girls Not Brides (Supported by secretariat, London, UK) revealed that $90 \%$ of adolescent births in the developing world are to girls who are already married or in a union. In most cases, child marriage is a driver of early pregnancy. They also concluded that early age marriages are at substantially greater risk of perinatal infant mortality and morbidity, and stillbirths and newborn deaths are 50\% higher in mothers under the age of 20 than in women who gave birth later. ${ }^{37}$ Our study also found that about $5 \%$ subjects got married at the age more than 30 years. According to research done by University of Rochester Medical Center woman's body goes through various physical and hormonal Changes after the age of 30. With each passing year, there is a decline in her fertility rate. The main reason behind this is that women in their 30s tend to ovulate less frequently, making conception harder than the women who ovulate regularly in their 20 s, thus leading to a late pregnancy. In the United States, birth rates for women in their 30s are at the highest levels in 4 decades. But an older mother may be at increased risk for things such as Miscarriage, Birth defects, Twins, High blood pressure, Gestational diabetes, difficult labor. ${ }^{38}$ For all women, about half of first trimester miscarriages happen because of a chromosome problem in the baby. The risk of chromosome problems in crease with the mothers age. So miscarriage is also more likely. ${ }^{38}$

We found that $72 \%$ subjects had their first child during the age group of 2130 while $19 \%$ subjects had their first child at their age under 20 years. While $6 \%$ had their first child when they were elder than 30 years of age. Report from the Health Girls Not Brides also suggests that early age pregnancy leads to higher risk of a pregnancy related complication. The risk for chromosome problems increases with the mother's age. The chance of having a child with Down syndrome increases over time. The risk is about 1 in 1,250 for a woman who conceives at age 25 . It increases to about 1 in 100 for a woman who conceives at age 40 . The risks may be higher. This is because many statistics only report live births. They do not note pregnancies with chromosome problems that ended due to pregnancy loss. After having 1 child with Down syndrome, the chance of having another baby with Down syndrome is higher. After age 40, the recurrence risk for Down syndrome is based on the age of the mother at delivery. Most babies with Down syndrome are born to women under the age of 35 . This is because women under the age of 35 have more babies than women over 35.38

According to Becker et.al, mothers education was the most consistent and important determinant of the use of child and maternal health services. Several other studies also found a strong positive im- pact of mother's education on the utilization of health services. ${ }^{3}$

As far as the knowledge status about antenatal care was concerned, our study found that $75 \%$ of the subjects were not aware of the antenatal care and about $100 \%$ were unknown regarding the necessity of antenatal check-up. The most probable reason for the reduced percentage of awareness for antenatal care is inadequate awareness / counselling modes. We noticed that most of the subjects had not gone through any awareness programs or counselling. In Indian scenario it becomes worse because of social stigma or shyness among the general public on the topics related to the pregnancy. In such condition the counselling can be an important tool to prevent the complications due to improper preg- nancy care. We observed that after our counselling there was an increase in percentage of both knowledge regarding antenatal care $(75 \%)$ and the necessity of antenatal check-up (100\%).

ANC visit is an essential part of the care but our study found that about $13 \%$ of the study subjects were not going for checkup. On interview with the subject it was revealed that 8 participants did not feel like 
Rafna Rafeek PM et.al. An evidence based assessment of pharmacist's intervention on pregnancy care knowledge and practice among the study subjects of Dakshina Kannada.

going for ANC check-up, while transport problem was reason among the 3 participants, 1 participant had family refusal and 1 participant was not there in the station. Good antenatal care includes regular screening which can detect and prevent early complication which can dramatically affect the foetus. According to Belland MB et.al, in Karnataka State, despite a high number of institutional deliveries, rate of still birth was $2.86 \%$. Maternal and new born mortality place significant bur- den on fragile health system with 3, 03,000 global maternal deaths annually. As due to lack of awareness and knowledge on pregnancy care it was found that there are 73 still births out of 193 births per 1000 population. Which if we expand in term of Indian population comes about 100 million still Births in a year due to lack in pregnancy care. ${ }^{11}$

Our report revealed that $88 \%$ of the study subjects were not aware of the necessity of TT injection. After giving counseling the figure got reversed and the awareness percentage reached to about $85 \%$ which was earlier $12 \%$, pre counsiling.

All pregnant ladies are recommended to go for their first antenatal check-up in the first trimester to identify and manage any medical complication as well as to screen them for any risk factors that may affect the progress and outcome of their pregnancy. In our study, 39\% were not aware that when first antenatal check-up should be done. Post counselling it was noticed that the unawareness percentage reduced to $15 \%$. Prenatal vitamins play a big part in the health of child. Additional key nutrients are typically found in folic acid and pregnancy multivitamins, both of which help support neural tube defects, baby's development, and the prevention of anemia. ${ }^{39}$ Regarding the knowledge about ANC care, >86 subjects knew about ironfolic acid supplementation. However we got satisfactory response on knowledge about the increase in food intake during pregnancy (76\%) but knowledge about adequate antenatal check-Up and screening test was poor.

\section{CONCLUSION}

The results revealed that most of the respondents did not have adequate knowledge regarding ANC services like antenatal care, folic acid supplementation, TT injection and dietary change. On enquiring about the reasons for inadequate utilization of ANC services, the major responses were non-awareness and affordability of services. Other factors like non-availability of transport facilities and family refusal were also reported. The age and literacy of the mother did not have significant influences on antenatal care and ANC service utilization. To improve effective utilization of ANC services, we need to raise awareness through counselling, improve the quality of ANC services, along with effective monitoring and evaluation. Reason behind ineffective utilization of ANC services, may be inadequate knowledge regarding ANC in our education system and inadequate counselling from the caring physician due to heavy patient load. This study emphasizes the importance of pharmacist as counselor for special population like pregnant women for better healthcare outcome.

\section{SUMMARY}

Appropriate Pharmacists intervention in Pregnancy care knowledge and Practice can maximize the net individual pregnancy care needs and thereby we can maximize the health condition of the pregnant women. The objective of the study was to assess the pharmacist intervention in pregnancy care knowledge and practice among the study subjects of Dakshina Kannada and to analyse the knowledge level of the subjects on pregnancy care, educate the community subjects on pregnancy care, Evaluate Pregnancy Information leaflet on pregnancy care. Aim of the study is to emphasize the need of community pharmacist's role in pregnancy care education. An interventional study was done 
in a population of 100 for a period of 6 months in Dakshina Kannada district.

The relevant data of the subjects collected using a data collection form. The collected data was analyzed using excel 17 and SPSS 20 and from the study conducted in a total of 100 participants only $12(12 \%)$ was aware about the need of injection TT but after the counseling it was increased to $85(85 \%)$ that is before counselling 88 (88 $\%$ ) was wrong after that it got reduced to $15(15 \%)$. In assessing the knowledge part of the study participants regarding the total dose of the injection TT during the pregnancy before counselling the rate of wrong answers was 85(85 \%) after counseling it reduced to 20 ( $20 \%$ ) and also initially only $15(15 \%)$ participants was correct and after counselling it increased to $80(80 \%)$.

In our study for accessing the need of folic acid tablet to women, we found that out of 100 participants many of them are unaware that is $91(91 \%)$ answered wrong initially ,but after counselling percentage of wrong answer reduced to $29 \%$. Study carried out in100 participants regarding whether the supplementation of iron and folic acid is good for mother and foetus, we found that majority that is87 (87\%) answered wrong initially, but after counseling percentage of wrong answer reduced to $36 \%$.

While assessing our study regarding the intake of food during pregnancy 76 participants told that it has to be increased 3 told that it has to be decreased and 16 says there is no need to make a change in the diet in pregnancy and also 4 participants not answered to this question.

From our study we came to know that from the total of 100 participants 76 increased the intake of leafy vegetable in pregnancy. 17 didn't made any change 4 participants decreased the intake and 4 participants did not answered this question. On query of Milk intake during pregnancy, from the 100 participants 78 participants increased,while 3 decreased and 16 participants didn't made any change and 3 didn't answered to the question. Assessing the fruit intake of 100 participants in pregnancy 76 increased, 1 decreased and 20 participants didn't make any change and 3 participants didn't answered to this question.

In our study from 100 participants regarding the meat intake in pregnancy 72 increased, 3 participants decreased and 23 didn't made any change also 3 not answered. About 86 participants out of the 100 participants was taking iron and folic acid in pregnancy while 7 was not taking 3 not answered. Regarding the total hours of rest required in pregnancy out of 100 participants 27 says that only less than 5 hours of rest required and 6 participants not answered to the question, 10 participants says that 5-6 hours of sleep required and 32 participants says that 7-8 hours of rest only, 25 participants says more than 8 hours of rest.

The study shows that majority of the women are unaware about the TT injection, folic acid tablet, and also dietary habits in pregnancy. So the intervention of the pharmacist role in creating awareness is essential.

As far as the knowledge status about antenatal care was concerned, the study found that $75 \%$ of the subjects were not aware of the antenatal care and about $100 \%$ were unknown regarding the necessity of antenatal check-up. The most probable reason for the reduced percentage regarding the antenatal care is due to unawareness of mothers regarding ANC. The increase in percentage of both knowledge regarding antenatal care $(83 \%)$ and the necessity of antenatal check-up (84\%) is done through counselling.

ANC visit should be an essential part of the care but our study found that about $13 \%$ of the study subjects were not going for check-up. On interview with the subject it was revealed that 8 participants did not feel like going for ANC check-up, while transport problem was reason among the 3 participants, 1 participant had family refusal 
and 1 participant was not there in the station.

Good antenatal care includes regular screening which can detect and prevent early complication which can dramatically affect the fetus. According to Belland MB et.al, in Karnataka State, despite a high number of institutional deliveries, rate of still birth were $2.86 \%$. Maternal and new born mortality place significant burden on fragile health system with 3, 03,000 global maternal deaths annually. As due to lack of awareness and knowledge on pregnancy care it was found that there are 73 still births out of 193 births per 1000 population. Which if we expand in term of Indian population comes about 100 million still births in a year due to lack in pregnancy care.

In our study found that $73 \%$ of the study subjects were not aware of the necessity of antenatal care so the knowledge regarding the doses of TT injection is also less. After giving counselling the wrong concepts of subjects got decreased to $8 \%$ tremendously.

In the current study, 39\% were not aware of when first antenatal check-up should be done. The first antenatal check-up should be done during the first 3 months and $66 \%$ does not have adequate knowledge regarding the number of antenatal checkups.

The results revealed that the respondents do not have adequate knowledge regarding ANC services like antenatal care, folic acid supplementation, TT injection and dietary change. On enquiring about the reasons for inadequate utilization of ANC services, the major responses were non-awareness and affordability of services. Other factors like non- availability of transport facilities and family refusal were also reported. The age, literacy of the mother significantly influences antenatal care and ANC service utilization. To improve effective utilization of ANC services, we need to raise awareness through counselling, improve the quality of ANC services, along with effective monitoring and evaluation. Pharmacist plays a major role in increasing awareness among mothers about the danger signals in pregnancy and further emphasizing the importance of ANC.

\section{Merits of the Study}

There are very few studies done on special population with an aim to assess the pharmacist intervention in their healthcare.

This study has proven clearly that pharmacist intervention can be an important tool for the awareness among the pregnant women on ANC.

\section{Limited duration of the study}

Relatively small numbers of participants due to special population limit the generalizability.

\section{Future Prospective:}

The study can be more efficiently carried out in large number of pregnant women which will provide sufficient data to generalize the benefit of pharmacist intervention.

Pharmacist can provide better awareness service and care to pregnant.

\section{ACKNOWLEDGEMENT}

We would like to express our gratitude to project guide Dr. Ateendra Jha, Associate Professor, Department of Pharmacy Practice, also be grateful to Principal of Srinivas College of Pharmacy for their valuable support.

\section{Conflict of Interest: None}

\section{Source of Funding: None}

\section{Ethical Approval: Approved}

\section{REFERENCES}

1. Introduction Ncbi.nlm.nih.gov. 2020 [cited 29 February 2020]. Available from: https://www.ncbi.nlm.nih.gov/books/NBK 409110/.

2. Pregnancy Symptoms. ucsfhealth.org. 2020 [cited 29 February 2020]. Available 
Rafna Rafeek PM et.al. An evidence based assessment of pharmacist's intervention on pregnancy care knowledge and practice among the study subjects of Dakshina Kannada.

from:

https://www.ucsfhealth.org/conditions/pre gnancy/trimesters.

3. Arya A, Mehra N. To Study the Knowledge, Attitude and Practices Regarding Antenatal Care among Pregnant Women in Haldwani Block, District Naintal (Uttarakhand) India. Journal of Medical Science And clinical Research. 2017; 05(04):20093-20102.

4. H. Danielewicz, G. Myszczyszyn. Diet in pregnancy-more than food NCBI. 2017 [cited 29 February 2020]. Available from: https://www.ncbi.nlm.nih.gov/pmc/article s/PMC5682869/

5. Kassaw A, Debie A. Quality of Prenatal Care and Associated Factors among Pregnant Women at Public Health Facilities of Wogera District, Northwest Ethiopia 2020 [cited 29 February 2020].

6. Daily iron and folic acid supplementation during pregnancy .World Health Organization.

7. 2020 [cited 1 March 2020]. Available from:

https://www.who.int/elena/titles/guidance _summaries/daily_iron_pregnancy/en/

8. Verma R, Khanna P. Vaccination during pregnancy: Today's need in India. Human Vaccine Immunotherapy. 2015 [cited 1 March 2020]. Available from: https://www.ncbi.nlm.nih.gov/pmc/article s/PMC4964703/

9. Gupta R, Talukdar B. Frequency and Timing of Antenatal Care Visits and Its Impact on Neonatal Mortality in EAG States of India. Journal of Neonatal Biology. 2017; 06 (03).

10. Alcohol Use in Pregnancy Centers for Disease Control and Prevention. 2020 [cited 1 March 2020]. Available from: https://www.cdc.gov/ncbddd/fasd/alcoholuse.html

11. Siddiqi K, Mdege N. A global perspective on smoking during pregnancy. The Lancet Global Health [Internet]. 2018 [cited 1 March 2020];6(7):708-709. Available from: https://doi.org/10.1016/S2214109X(18)30246-8

12. Bellad M, Vidler M, Honnungar N, Mallapur A, Ramadurg U, Charanthimath $\mathrm{U}$ et al.
13. Maternal and Newborn Health in Karnataka State, India: The Community Level Interventions for Pre- Eclampsia (CLIP) Trial's Baseline Study Results. PLOS ONE. 2017; 12(1):e0166623.

14. Vlemmix F, Warendorf JK, Rosman AN, Kok M, Mol BW, Morris JM, Nassar N. Decision aids to improve informed decision-making in pregnancy care: a systematic review. BJOG: An International Journal of Obstetrics \& Gynaecology. 2013 Feb; 120(3):257-66.

15. Truong MB, Ngo E, Ariansen H, Tsuyuki RT, Nordeng H. Community pharmacist counselling in early pregnancy-Results from the Safe Start feasibility study. PloS one. 2019 Jul 19; 14 (7):e0219424.

16. Leung HY, Saini B, Ritchie HE. Medications and pregnancy: The role of community pharmacists-A descriptive study. PloS one. 2018 May 9; 13(5):e0195101.

17. Sedgh G, Singh S, Hussain R. Intended and unintended pregnancies worldwide in 2012 and recent trends. Studies in family planning. 2014 Sep; 45(3):301-14.

18. Albassam A, Awad A. Community pharmacists' services for women during pregnancy and breast feeding in Kuwait: a cross-sectional study. BMJ open. 2018 Jan1; 8(1):e018980.

19. Samuel N, Einarson A. Medication management during pregnancy: role of the pharmacist. International journal of clinical pharmacy. 2011 Dec 1; 33(6):8825.

20. Nair H, Panda R. Quality of maternal healthcare in India: Has the National Rural Health Mission made a difference?. Journal of global health. 2011 Jun; 1(1):79.

21. Matthews Z, Mahendra S, Kilaru A, Ganapathy S. Antenatal care, care-seeking and morbidity in rural Karnataka, India: results of a prospective study. Asia Pacific Population Journal. 2001 Jun; 16(2):1128.

22. Vincent A, Keerthana K, Damotharan K, Newtonraj A, Bazroy J, Manikandan M. Health care seeking behaviour of women during pregnancy in rural south India: a qualitative study. International Journal of 
Rafna Rafeek PM et.al. An evidence based assessment of pharmacist's intervention on pregnancy care knowledge and practice among the study subjects of Dakshina Kannada.

Community Medicine and Public Health. 2017 Sep 22; 4(10):3636-9.

23. Mistry R, Galal O, LuM. Women's autonomy and pregnancy care in rural India: a contextual analysis. Social science \& medicine. 2009 Sep 1; 69(6):926-33.

24. Lale S ,Rosalind R, A systematic review of inequalities in the use of maternal health care in developing countries: examining the scale of the problem and the importance of context, Bulletin of the World Health Organization | October 2007, 85 (10).

25. Houweling T, Ronsmans C, Campbell O, Kunst A ,Huge poor-rich inequalities in maternity care: an international comparative study of maternity and child care in developing countries, Bulletin of the World Health Organization | October 2007, 85 (10).

26. Geta M, Yallew W. Early Initiation of Antenatal Care and Factors Associated with Early Antenatal Care Initiation at Health Facilities in Southern Ethiopia. Advances in Public Health. 2017;2017:16.

27. Ibnouf A, Van den Borne H, Maarse J. Utilization of family planning services by married Sudanese women of reproductive age. Eastern Mediterranean Health Journal. 2007;13(6):1372- 1381.

28. Nigenda G, Langer A, Kuchaisit C, Romero M, Rojas G, Al-Osimy $\mathrm{M}$ et al. Womens' opinions on antenatal care in developing countries: results of a study in Cuba, Thailand, Saudi Arabia and Argentina. BMC Public Health. 2003;3(1).

29. Matthews Z, Mahendra S, Kilaru A, Ganapathy S, Antenatal Care, Careseeking and Morbidity in Rural Karnataka, India: Results of a Prospective Study, Asia-Pacific Population Journal, Vol. 16, No.2.

30. Berhan Y, Berhan A, Antenatal Care as a Means of Increasing Birth, the health facility and reducing maternal mortality: a systematic review, Ethiop J Health Sci.Special Issue September 2014.

31. Dixit P , Dwivedi L , Ram F, Estimating the impact of antenatal care visits on institutional delivery in India: A propensity score matching analysis http://dx.doi.org/10.4236/

health.2013.55114 Vol.5, No.5, 862-878 (2013) .

32. Chandhiok N, Dhillon B, Kambo I, Saxena Determinants of antenatal care utilization in rural areas of India : A cross-sectional study from 28 districts (An ICMR task force study), The Journal of Obstetrics and Gynecology of India,Vol. 56, No. 1 : January/February 2006 Pg 47- 52.

33. Solnes Miltenburg A, van der Eem L, Nyanza E, van Pelt S, Ndaki P, Basinda $\mathrm{N}$ et al,Antenatal care and opportunities for quality improvement of service provision in resource limited settings: A mixed methods study, PLOS ONEhttps://doi.org/10.1371/ journal.pone.0188279 December 13, 2017

34. Patel B, Gurmeet P, Sinalkar D, Pandya K, Mahen A, Singh N. A ,A study on knowledge and practices of antenatal care among pregnant women attending antenatal clinic at a Tertiary Care Hospital of Pune, Maharashtra ,http://www.mjdrdypu.org on Friday, March 20, 2020, IP: 117.221.154.251 .

35. M. Rani et al,Differentials in the quality of antenatal care in India, International Journal for Quality in Health Care 2008; Volume 20, Number 1: pp. $62-71$.

36. K. S. Sugathan, Mishra V, Retherford R, Promoting Institutional Deliveries In Rural India: The Role of Antenatal-Care Services, National Family Health Survey Subject Reports, No. 20. December 2001.

37. Hijazi H, Alyahya M, Sindiani A et al,Determinants of antenatal care attendance among women residing in highly disadvantaged communities in northern Jordan: a cross- sectional study, Reproductive Health (2018) 15:106https://doi.org/10.1186/s12978018-0542- 3

38. Kumar G, Choudhary T, Srivastava A, et al,Utilisation, Equity And Determinants Of FullAntenatal Care In India: Analysis From The National Family Health Survey 4,BMC Pregnancy and Childbirth volume 19, Article number: 327 (2019). 
Rafna Rafeek PM et.al. An evidence based assessment of pharmacist's intervention on pregnancy care knowledge and practice among the study subjects of Dakshina Kannada.

39. Brides G. What is the impact of child marriage? - Girls Not Brides. 2020 [cited 14 March2020]. Available from: https://www.girlsnotbrides.org/what-isthe-impact

40. Risks of Pregnancy Over Age 30 - Health Encyclopedia - University of Rochester Medical Center .Urmc.rochester.edu. 2020 [cited 14 March 2020]]. Available from: https://www.urmc.rochester.edu/encyclop edia/content.aspx

41. The Importance of Antenatal Care - Blog | St John Medical [Internet]. St John Health. 2020 [cited 14 March 2020].
Available from:

https://www.stjohnhealth.com.au/blog/me dical/antenatal-care-essential/Why

Antenatal Care is Essential [Internet]. St John WA. 2020 [cited 14 March 2020]

How to cite this article: Rafna Rafeek PM, Roshna. P, Jha A et.al. An evidence based assessment of pharmacist's intervention on pregnancy care knowledge and practice among the study subjects of Dakshina Kannada. International Journal of Research and Review. 2021; 8(7): 420-435. DOI: https://doi.org/10.52403/ijrr.20210760 